\title{
TEORIA DOS JOGOS APLICADA Á CONTABILIDADE
}

Mary Tsutsui Bontempo

Mestranda em Controladoria e Contabilidade pela FEA/USP

Consultoria da Maluf \& Guimarães Empresarial S/C

\section{Introdução}

A Teoria da Contabilidade está passando, neste processo final do século $X X$, por um profundo processo de questionamento quanto a sua metodologia cientifica e ao cumprimento de seus objetivos. Quanto á metodologia, são criticadas a falta de rigor na utilização da terminologia contábil, gerando discussões infrutíferas devido ao entendimento que cada oponente tem da linguagem contábil e a ausência de um tratamento mais formal, estatístico, matemático e lógico dos problemas contábeis. Quanto ao cumprimento dos objetivos, são censuradas e falta de clareza e as próprias informações fornecidas pelas demonstrações financeiras que, muitas vezes, não condizem com as expectativas e as necessidades informativas dos diversos usuários desses produtos.

Em face do contexto apresentado, os objetivos deste arquivo são: enfocar o objetivo da Contabilidade sob o ângulo da empresa fornecedora das informações contábeis e ver as informações como um precioso ativo da empresa, cuja exposição completa pode implicar em conseqüências estratégicas negativas para a organização e também sugeria a utilização de uma abordagem matemática, a Teoria dos Jogos, já amplamente incorporada na Ciência Econômica, para analisar $\mathrm{p}$ processo decisório dos diversos usuários da informação contábil e dar subsídios para as empresas decidirem como agir em face das demandas dos diversos usuários, quanto ás suas informações contábeis.

\section{Objetivos e Usuários da Contabiliade}

Segundo o American Institute of Certified Public Accountants - AICPA, a função fundamental da Contabilidade é prover os usuários dos demonstrativos financeiros com informações úteis que os ajudarão a tomar decisões.

Este objetivo tem permanecido inalterado durante o tempo e não há muitas controvérsias a respeito, no entanto, o meio de cumpri-lo ainda não obteve um consenso tanto em termos práticos quanto acadêmicos.

- acionistas minoritários e majoritários;

- gestores da empresa;

- banco de outros credores;

- investidores potenciais;

- órgãos governamentais federais, estaduais e municipais;

- estudiosos do setor

- empregados atuais e potenciais;

- empresas concorrentes e parceiros comerciais;

- clientes fornecedores atuais e potenciais;

Cada um desses grupos de usuários e os mesmos usuários individuais, dentro de um determinado grupo, necessita de informações diferentes de acordo com as decisões que precisam tomar em dado período de tempo, demandado um conjunto de informações próprio. 
Portanto, o segundo problema é: como fornecer demonstrações financeiras que satisfaçam toda esta diversidade e expectativas e que também mudem com o decorrer do tempo?

Existem basicamente três soluções distintas para o problema proposto:

- fornecer informações individualizadas de acordo com a demanda

- fornecer informações corretas, que reflitam efetivamente os impactos patrimoniais dos eventos realizados:

- a alternativa anterior combinada á manutenção de um detalhado banco de dados que possibilite a confecção de relatórios personalizados, de acordo com solicitações individuais.

Nas três soluções acima, no entanto, esta implícita a hipótese de que a empresa deve fornecer as informações demandadas pelos usuários e que o problema está apenas em como faze-lo.

Do ponto de vista da empresa, as informações contábeis são consideradas um ativo valioso e também custoso, para serem amplamente expostas. Por um lado, o ambiente empresarial atual é bastante dinâmico, competitivo e complexo, exigindo das empresas uma postura estratégica que considere todos os fatores a sua volta, o que inclui os usuários contábeis como os investidores, bancos e acionistas, Por outro lado, há interesse também dos concorrentes, governo e trabalhadores ávidos por informações detalhadas á respeito das estratégias futuras e dos resultados passados da empresa em foco para subsidiar o próprio comportamento em relação á empresa.

Assim o objetivo da Contabilidade, sob o ponto de vista da empresa, é um fator estratégico importante para o seu posicionamento competitivo e que precisa de uma definição quanto ao comportamento adequado em relação ao fornecimento ou não, e o modo de divulgar as informações contábeis demandadas pelos diversos usuários. A questão portanto é: Que técnica a empresa deve utilizar para definir seu posicionamento em relação as demonstrações contábeis?

Cabe ressaltar que o governo é usado antipico em relação às informações contábeis em razão de seu poder legislativo que the permite instituir a divulgação compulsória das demonstrações financeiras de acordo com as próprias necessidades informativas e também de pressões por parte da sociedade como um todo.

\section{$\underline{\text { Teoria dos jogos }}$}

A Teoria dos Jogos começou a ser desenvolvida em 1928 pelo matemático John Von Neumann abordando inicialmente os jogos de estratégia, como xadrez e damas. Com a colaboração do economista Oskar Morgenstern, esta teoria passou a ser aplicada também aos problemas econômicos, resultando na primeira publicação completa da Teoria dos Jogos e de suas aplicações econômicas em 1944, no livro de Theory of Games and Economic Behavior de autoria de dois cientistas.

Nos últimos cinqüenta anos, a Teoria dos Jogos vem sendo aperfeiçoada de modo a abranger situações mais próximas da realidade e apresentar soluções matemáticas para estes casos.

Em 1994, três economistas, John Nash, Reinhard Selten e John Harsanyi receberam o Prêmio Nobel por suas contribuições neste campo.

Atualmente, a Teoria dos Jogos é, juntamente com a Teoria de Caos, uma das áreas mais importantes de pesquisa no campo econômico devido a sua grande possibilidade de aplicação prática e ao rigor matemático que sustenta suas conclusões.

Um exemplo clássico desta teoria é o dilema dos prisioneiros que ilustra de forma simples o alcance e as possibilidades de desenvolvimento deste campo:

Dois suspeitos de um crime (que realmente cometeram conjuntamente) são detidos pela policia e interrogados em celas separadas. Para cada um deles, a policia diz: "Se vocês dois confessarem, cada um ficará seis anos preso. Se você confessar e seu parceiro não, você ficará preso apenas pela sua colaboração e o outro dez anos, pela resistência. Se ninguém confessar, ambos ficarão presos quaro anos. Portanto, o melhor é você confessar." 
Apresentação gráfica do dilema dos prisioneiros é a seguinte:

\begin{tabular}{|lcc|}
\hline \multicolumn{3}{|c|}{ Suspeito B } \\
\hline Suspeito A & Confessar & Não confessar \\
\hline Confessar & $(-6 ;-6)$ & $(-2 ;-10)$ \\
\hline Não confessar & $(-10 ;-2)$ & $(-4 ;-4)$ \\
\hline
\end{tabular}

Para cada Suspeito, a sua pena é menor se optar por confessar (dois ou seis anos de prisão, dependendo da decisão do companheiro); portanto, se os prisioneiros não se comunicarem, os dois confessaram e ficarão seis anos presos.

No entanto, no anterior mostra que se ninguém confessar, a pena é de quatro anos para cada um, ou seja, é a melhor solução para os prisioneiros e o seu dilema.

Este exemplo simples ressalta as principais contribuições da Teoria dos Jogos: a independência das estratégias dos jogadores e que neste caso a otimização da solução individual pode não significar a otimização da solução coletiva.

Para a aplicação da Teoria dos Jogos em algum problema é preciso verificar se existe um jogo.

Uma definição geral de jogo é: qualquer situação regida por regras com um resultado definido, caracterizada pela independência estratégica.

Assim, esta definição abrange não só o que se chama geralmente de jogos como: xadrez, futebol, cartas, mas também uma série de outras situações do cotidiano.

Por exemplo: bancos atuando no mercado financeiro pode ser considerado um jogo, pois, conforme a definição acima:

- há regras formais e informais para a atuação dos bancos;

- existe um resultado definido representado pelo lucro maior ou menor de acordo com o desempenho da instituição;

- o resultado de cada banco depende não só da própria estratégia, mas também da estratégia dos outros agentes econômicos.

- os jogos podem ser alocados em diferentes categorias, apresentado soluções distintas de acordo com a sua classificação:

- Jogo de soma constante - neste caso, os interesses dos jogadores são totalmente antagônicos, pois, como o resultado do jogo constante, para um jogador ganhar, necessariamente os imponentes devem perder. O jogo de xadrez é um exemplo de jogo de soma constante, pois os resultados possíveis são (jogador A ganhar, jogador B perder); (jogador A perder, jogador B ganhar) e (jogador A empatar, Jogador B empatar), ou seja, para o jogador A melhorar seu resultado, o jogador B precisa piorar e vice-versa.

- Jogos de soma variável cooperativos - nos jogos de soma variável existem situações em que todos ou pelo menos alguns jogadores estão em posições mais favoráveis que na situação anterior. Nestes jogos, portanto, há a possibilidade de um barganha entre os jogadores para alcançar um resultado melhor ou, pelo menos indiferente para todos os participantes. O problema da cooperação é que a posição do consenso é a melhor enquanto todos respeitarem o acordo, mas a recompensa por alguém obedecer é grande.

- Jogos de soma variável não-cooperativos - o dilema dos prisioneiros, apresentado anteriormente, é um exemplo destas categorias de jogos. A cooperação não é possível, como no 
caso dos prisioneiros em celas separadas, ou não existe disposição para a cooperação. Nestes jogos, cada jogador escolhe a estratégia que rende os maiores resultados para si próprio, dadas as estratégias que os outros jogadores devem escolher. No entanto, como no dilema dos prisioneiros, a racionalidade individual pode levar a um resultado conjunto não-ótimo.

Cada uma destas categorias de jogos é por sua vez dividida de acordo com o nível de informação dos participantes: quanto á informação é perfeita, todos os jogadores tem todas as informações disponíveis em relação a si próprios e aos seus oponentes. Quanto a informação é imperfeita alguns jogadores têm informações privilegiadas quanto ao jogo e aos jogadores, ou estes último, não tem todas as informações a respeito dos primeiros.

O ambiente econômico e as entidades, que são objeto de estudo da Contabilidade, podem ser classificadas como uma complexa mistura de jogos de soma variável cooperativos e jogos de soma variável não-cooperativos com informação imperfeita. A existência de interesses comuns por parte de alguns jogadores possibilita a cooperação e a construção de acordos de modo a aumentar a posição relativa do grupo no jogo econômico: no entanto, a existência de uma diversidade de jogadores com objetivos diferentes impede a cooperação total. A informação é imperfeita, ou seja, não esta disponível igualmente para todos os jogadores por causa das questões de ordem prática com o tempo, custo, tecnologia, etc.

Os jogos não-cooperativos podem ser representados simplificadamente a partir da identificação de três fatores:

- a lista de participantes;

- para cada jogador; a lista de estratégias;

- para cada vetor de estratégias, um para cada jogador, uma lista das recompensas jogadores.

No caso do dilema dos prisioneiros, já visto:

• os jogadores são:suspeito A e suspeito B;

- para cada um dos jogadores, a lista de estratégias compôe-se das opções confessar ou não confessar;

- para cada um dos jogadores, a lista de resultados possíveis é prisão por dois anos, prisão por quatro anos ou prisão por seis anos.

A partir das três informações é possível construir o diagrama apresentado anteriormente que mostra de forma visualmente fácil as várias combinações de estratégias e seus respectivos resultados, favorecendo o raciocínio lógico.

\section{Teoria dos Jogos Aplicada à Contabilidade}

Nesta seção será estudada a possibilidade da aplicação dos Jogos à Contabilidade, particularmente no que se refere ao objetivo da Contabilidade e ás suas conseqüências para as empresas.

Primeiramente, é necessário verificar se o problema a ser estudado é realmente um jogo, segundo a definição apresentada anteriormente; depois, classifica-la, segundo suas características e, então, verificar se a Teoria dos Jogos já desenvolveu uma solução satisfatória para tais modelos.

Neste trabalho, o objetivo da Contabilidade é considerado conforme a visão da empresa, isto é, a empresa é uma fornecedora de informações contábeis para diferentes usuários que tomam 
decisões baseadas nestas e outras informações disponíveis. Os usuários demandam informações detalhadas para diminuírem suas incertezas. A empresa por sua vez, precisa decidir se fornece mais informações do que a legislação vigente exige, ou se não divulga informações adicionais voluntariamente.

Com base na definição de jogo apresentada anteriormente, vê-se que:

- existem regras que governam o fornecimento e a exigência de informações por parte dos usuários;

- um resultado concreto advém da interação entre os agentes, isto é, mais ou menos lucro para a empresa e os usuários;

- as estratégias dos agentes são interdependentes, ou seja, as decisões de um afetam as decisões dos outros componentes;

Portanto, segundo estas considerações, a interação entre os usuários da informação contábil pode ser considerada um jogo.

Analisando mais detalhadamente os usuários das demonstrações financeiras descritos anteriormente, conclui-se que este jogo pode ser classificado como um jogo com a soma variável não-cooperativo com informações imperfeita.

O jogo é a soma variável porque o resultado possível do jogo, ou seja, a soma dos resultados individuais não é constante, dado que, de posse das informações contábeis, um determinado usuário pode adicionar valor à economia sem prejuízos aos demais usuários.

No entanto, o jogo é não-cooperativo porque existem interesses conflitantes entre diversos usuários, de modo que não é possível construir um acordo estável que forneça todos os jogadores. Por exemplo: é interessante para a empresa divulgar seus bons resultados e seus planos de investimento de modo a atrair novos investidores no mercado e tranqüilizar seus credores e acionistas; no entanto, estas informações podem também atrair a atenção do governo que verá perspectivas de maiores impostos e também uma fiscalização maior para coibir abusos. Os concorrentes, do mesmo modo, serão aguçados a procurar melhores oportunidades e a competirem mais acirradamente.

As informações são imperfeitas, como na maioria das situações econômicas, porque a disponibilidade de todas as informações a todos os usuários e praticamente impossível de se atingir, por problemas tecnológicos, altos custos, interesses, etc.

Os jogos de soma variável não-cooperativos apresentam uma solução através do conceito de equilíbrio de Nash. Um conjunto de estratégias é considerado um equilíbrio de Nash, quando nenhum jogador consegue um resultado maior somente ele muda de estratégia. Cabe ressaltar que um jogo pode ter mais que um equilíbrio de Nash e que nas últimas décadas estão em desenvolvimento diversos aperfeiçoamentos desta teoria, de modo a possibilitar uma única e também comportamentos diferentes da racionalidade puramente econômica, por parte dos jogadores.

O fato dos jogadores terem informação imperfeita em relação aos seus adversários também introduz dificuldades e a necessidade de utilização de técnicas matemáticas mais complexas na resolução desta categoria de jogos. Devido ao caráter exploratório deste artigo, estes tópicos não foram tratados.

\section{Conclusões}

A Teoria dos Jogos é um instrumento matemático, que teve seu desenvolvimento largamente influenciado pela sua aplicação na Teoria Econômica, mas que também pode ser utilizado em diversos outros campos de conhecimento humano. A Contabilidade, ao lidar com empresas, informações, tomada de decisão e suas interações, mostra-se um candidato natural para a aplicação da Teoria dos Jogos.

Dado que a Contabilidade esta vivendo períodos de incertezas quanto à metodologia cientifica a ser empregada, precisando de uma abordagem mais formal e lógica de seus problemas 
e também passando por uma certa desconfiança quanto à validade e rigor das informações produzidas, vislumbra-se um momento.propício para procurar uma interação maior com as áreas afins como a Economia, Administração e a Matemática. Desse modo, a Contabilidade pode modernizar seus conceitos contábeis e inserir-se no atual contexto em que as fronteiras entre as ciências estão acabando, exigindo uma visão cada vez mais ampla e interdisciplinar por parte dos cientistas e todas as áreas.

Para atingir o objetivo da Contabilidade de suprir de suprir informações úteis aos tomadores de decisão, é preciso conhecer como funciona o processo decisório dos diversos grupos envolvidos. Para tanto, pode-se pesquisar o funcionamento do pensamento humano utilizando-se a psicologia, ou suponha-se que os agentes decidem com base em uma racionalidade econômica, sem considerar juízos de valor.

A Teoria dos Jogos é uma ferramenta interessante para analisar o comportamento humano, pois ao explicitar as diversas estratégias possíveis e suas interdependências, várias ações, que a principio parecem irracionais, são explicadas logicamente, isto é, pela racionalidade econômica, facilitando a compreensão da complexa realidade econômica e social vivida atualmente.

O caráter exploratório deste artigo não permite obter um resultado concreto da aplicação da Teoria dos Jogos á Contabilidade mas já indica que é possível e promissora a sua utilização para o estudo do comportamento dos usuários das demonstrações financeiras.

\section{$\underline{\text { Resumo }}$}

Este arquivo enfoca o objetivo da Contabilidade de fornecer informações úteis para a tomada de decisões, sob o ângulo da empresa provedora destas informações. A organização vê as informações contábeis como um precioso e custoso ativo cuja exposição completa pode explicitar conseqüências estratégicas negativas em um ambiente competitivo e globalizado como 0 vivido atualmente.

Assim, sugere-se a utilização de uma abordagem matemática, a Teoria dos Jogos, já amplamente incorporada à Ciência Econômica, para analisar o processo decisório dos diversos usuários da informação contábil e dar subsídios para as empresas decidirem como agir, face as demandas dos diversos usuários por suas informações contábeis.

A aplicação sugerida é um pequeno exemplo das contribuições potenciais de uma abordagem formal e interdisciplinar à metodologia contábil existente.

\section{Referências Bibliográfica}

DIXIT, Avinash. E NALEBUfF, Barry J. Pensando Estrategicamente: a Vantagem Competitiva nos Negócios, na política e no Dia-a-Dia. São Paulo: Atlas, 1994

GARDNER, Roy. Games for Business and Economics. New York: John Wiley \& Sons, 1995.

HENDRIKSEN, Eldon S. Accouting Theory. Illinois. Richard Irwin, 1977.

IUDICIBUS, Sérgio de. Teoria da Contabilidade. São Paulo: Atlas, 1995.

KREPS, Davis M.Game Theory and Economic Modelling. Oxford: Claredon Press, 1990.

NEUMANN, John von and MORGENSTERN, Oskar. Theory of Games and Economic Behavior. New Jersey: Priceton University Press, 1947 